\section{TURISMO GENTRIFICADOR EN CIUDADES PATRIMONIALES. EXCLUSIÓN Y TRANSFORMACIONES URBANO-AROUITECTÓNICAS DEL PATRIMONIO EN GUANAJUATO, MÉXICO*}

David Navarrete Escobedo**

\section{Resumen}

En América Latina numerosos centros históricos experimentan diversos grados de gentrificación asociada al turismo. Es el caso de varias ciudades mexicanas patrimonializadas, que transforman sus usos y espacios al consumo de visitantes. Este trabajo explora dicha tendencia en una de sus más acabadas expresiones: la hotelería de lujo como vector transformador de la vocación del patrimonio construido de una ciudad. Por medio del caso de Guanajuato (centro-oeste de México), se analizan las principales transformaciones arquitectónicas y urbanas que derivan de una elitización de las

\section{GENTRIFYING TOURISM IN HERITAGE CITIES. EXCLUSION AND URBAN- ARCHITECTURAL TRANSFORMATION IN GUANAJUATO, MEXICO*}

David Navarrete Escobedo**

\section{Abstract}

Numerous historic city centers in Latin America have been gentrified as the result of tourist activities. This is the case of several heritage Mexican cities that transformed their uses and spaces according to the consumption needs of visitors. This paper explores this trend in one of its most complete manifestations: luxury hotels as a tool in the transformation of the heritage of the city. Analysis of the case of Guanajuato (westcentral Mexico) reviews the main architectural and urban transformations derived from the 
ciudades turísticas patrimoniales. Los nuevos usos turísticos cambian de forma importante las tipologías patrimoniales y tradicionales, generando una arquitectura fachadista al mismo tiempo que acentúan procesos de exclusión y fragmentación social en los centros históricos en los que se implantan. El turismo de élite se muestra como un factor transformador de la ciudad, no sin contradicciones pues los recursos culturales, patrimoniales y sociales, de los que depende el prestigio del destino pueden verse amenazados por la explotación turística. En tales procesos el Estado, el mercado y una débil ciudadanía aparecen como factores determinantes.

PALABRAS CLAVE: GENTRIFICACIÓN, TURISMO, HOTELERÍA, TIPOLOGÍA ARQUITECTÓNICA, PATRIMONIALIZACIÓN

Recibido: 11-08-2015

Aceptado: 17-05-2016

* Este artículo forma parte del programa de investigación desarrollado durante los años 2015-2017 en el Departamento de Arquitectura de la Universidad de Guanajuato, en la línea de investigación Turismo, Cultura y Territorio.

* México. Doctor en urbanismo. Profesor del Departamento de Arquitectura de la Universidad de Guanajuato. Correo electrónico: davnav25@hotmail.com gentrification of heritage tourist cities. The new tourist uses modify heritage and traditional typologies, giving rise to a façade-based architecture and exacerbate social exclusion and fragmentation processes in historic centers. Luxury tourism emerges as a contradictory transforming factor as it may threaten the natural, heritage and social resources that sustain this activity. In this context, the State, the market and a weak citizenship are deciding factors.

KEYWORDS: GENTRIFICATION, TOURISM, HOTEL INDUSTRY, ARCHITECTURAL TYPOLOGY, HERITAGE

Received: 11-08-2015

Accepted: 17-05-2016

* This paper is part of a tourism, culture and territory research program developed from 2015 to 2017 at the Department of Architecture, University of Guanajuato.

* Mexico. PhD in Urban Development. Professor, Department of Architecture, University of Guanajuato. Email: davnav25@ hotmail.com. 


\section{Introducción}

\section{TURISMO Y GENTRIFICACIÓN, DINÁMICAS EMERGENTES DE LOS CENTROS HISTÓRICOS PATRIMONIALES}

A nivel mundial a partir de 1970, las condiciones económicas y políticas evolucionaron consolidando las tendencias a la desindustrialización, al desarrollo del sector terciario y a la globalización de zonas centrales en un buen número de ciudades y regiones urbanas. Para el urbanista francés Olivier Mongin $^{1}$ el desplazamiento de la industria como principal actividad de la metrópoli ha dado como resultado primero un abandono (de edificios, predios industriales, puertos, expropiaciones ferroviarias) y luego una museificación en una lógica de terciarización de la base económica urbana; es decir su conversión en museos, galerías, óperas, bibliotecas, hoteles boutique. En América Latina la terciarización de los sectores centrales se vio acompañada de una sobre-especialización comercial en perjuicio del uso habitacional de todas las categorías socioeconómicas de residentes ${ }^{2}$. El abandono habitacional de las áreas centrales se aceleró por la implantación en periferia de actividades industria-

1 Mongin, 2005, p. 149.

2 Monnet, 1995. les y de urbanizaciones espontáneas, al menos en las principales metrópolis latinoamericanas. Entre 1970 y 2000 el debilitamiento general de la centralidad histórica, el desbordamiento de los límites administrativos de las ciudades y una urbanización desbordada, marcaron las dinámicas urbanas del crecimiento de muchas ciudades mexicanas. El debilitamiento de la centralidad histórica se caracterizó por una subutilización de infraestructuras, una pérdida de densidad, una menor mezcla de usos de suelo y un abandono del capital inmobiliario en zonas con importantes contenidos de edificios patrimoniales.

Durante las últimas décadas del siglo XX e inicios del XXI, el abandono del centro histórico dio paso a dos fenómenos urbanos tendenciales de varias ciudades tanto latinoamericanas como a nivel mundial: la gentrificación y la turistificación ${ }^{3}$. Dichos procesos son reconocibles principalmente en las grandes metrópolis nacionales y regionales para el caso de América Latina (Ciudad de México, Buenos Aires, Santiago de Chile, la Habana, Lima, São Paulo, entre otras). Igualmente dan signos de presencia en ciudades de menor tamaño, pero con un patrimonio construido sustancial y bien conservado; (Cartagena, Guanajuato, Morelia, San

3 La gentrificación y, de forma tangencial, la turistificación han sido tratadas recientemente en trabajos relevantes en el área de la sociología, la economía y el urbanismo. Es el caso de Sassen, 1996; Harvey, 1998; Paquot, 2006; Florida, 2002, Ascher, 2001 y Mongin, 2005. 
Miguel de Allende, Valparaíso, Salvador de Bahía, entre otras). Es importante mencionar que no en todos los centros históricos encontramos niveles significativos ni de gentrificación ni de turistificación. Ha existido una serie de condiciones además de las ya mencionadas en el párrafo anterior (debilitamiento de la centralidad, la pérdida de uso habitacional y la especialización comercial), que ha determinado que ciertos centros históricos sean más propensos a procesos de renovación vía usos y usuarios de superiores niveles de consumo. Esas condiciones son esencialmente políticas y económicas. Para las primeras tenemos dos factores relevantes, uno es una declaratoria internacional de protección, específicamente la concedida por la UNESCO; otro es una política de regeneración urbana que incluye expresamente al turismo y que aquí designaremos como turistificación. Para las condiciones económicas tenemos que el potencial de recuperación del valor del patrimonio del centro histórico debe ser suficientemente amplio para que el Capital decida invertir en su regeneración urbana. En otros términos el centro histórico se tiene que dejar devaluar lo suficiente en términos de valor del suelo, para que resulte conveniente comprar barato y vender a precios elevados según actividades y perfiles de usuarios con mayor poder adquisitivo. Simplificando, se puede distinguir que una declaratoria de la UNESCO, más una política de regeneración urbana promovida por el Estado y/o el gobierno local, más condiciones empresariales ventajosas, resultarán niveles significativos de gentrificación y turistificación.

En ese contexto, la turistificación, traducción literal del término francés touristification ${ }^{4}$ designa el proceso y el resultado de un desarrollo turístico planificado y voluntarista de un espacio, para nuestro fines de un área urbana central patrimonial. Se trata de la apropiación a través del tiempo de una ciudad por el turismo. Ella se manifiesta por la ocupación progresiva de hoteles y equipamientos para visitantes, por una polarización creciente de flujos turísticos (en tiempo y espacio) y por efectos diversos en términos socioeconómicos para la ciudad visitada. El término también hace alusión a la parte excesiva que el turismo ocupa en las actividades urbanas.

Por su parte, la gentrificación plantea la sustitución masiva de clases obreras residentes en barrios centrales, por clases superiores 5 . Ella, matizada en Latinoamérica apuntaría más a una ocupación real y simbólica de los espacios tanto públicos como privados por parte de clases privilegiadas con altos niveles adquisitivos. Según Martínez ${ }^{6}$, la renova-

\footnotetext{
Dewailly, 2005, p. 31.

5 Glass, 1964.

6 Martínez, 2004, citado en Vergara, 2013.
} 
ción de los centros en América Latina ha tenido como consecuencia el alza del valor del suelo, la transformación de uso de suelo, la rehabilitación de viejas viviendas degradadas, la construcción de nuevos establecimientos comerciales, una nueva concepción del espacio público y la reconversión de áreas industriales en equipamientos urbanos o actividades terciarias. El resultado es que la ciudad se adapta al consumo de un alto poder adquisitivo en detrimento de poblaciones con menores recur$\operatorname{sos}^{7}$. Por lo observado en Latinoamérica más que una gentrificación residencial (acepción original de los países del norte), se trata de una gentrificación de actividades económicas asociadas frecuentemente al turismo, lo que Fernando Carrión define como boutiquinización ${ }^{8}$.

En el estudio de la gentrificación en Latinoamérica, que se ha desarrollado en zonas centrales y patrimoniales de grandes ciudades, se pueden distinguir al menos dos importantes líneas:

-La gentrificación sin expulsión. Es decir que no hay una sustitución masiva de habitantes de menores ingresos por otros de mayores. Son los casos de Ciudad de México, Buenos Aires, Santiago de Chile, Río de Janeiro o la Habana9.

7 Boldrini, 2014, p. 160.

8 Carrión, 2007.

9 Sabatini, 2009; Carrión, 2007; Vergara, 2013; Casgrain, 2013.
-La gentrificación en actividades productivas. Es decir que se trata de cambio de uso de suelo habitacional o mixto con actividades comerciales tradicionales a un uso comercial y de servicios con vocación internacional, principalmente en las actividades del turismo cultural y del turismo de negocios, de las finanzas, de los servicios corporativos, de instancias gubernamentales internacionales y de sectores económicos relacionados con el conocimiento, la comunicación y la información ${ }^{10}$.

Con las consideraciones precedentes proponemos el argumento principal de esta investigación, a saber, que en el contexto latinoamericano surge un tipo de gentrificación derivada de la adaptación planificada de los sectores centrales a los visitantes, es decir de su turistificación. Esta modalidad resulta de la relación dialéctica de esos dos fenómenos y se caracterizaría, tal como lo pretendemos ilustrar con nuestro caso de estudio, por una gentrificación basada esencialmente en la transformación del uso y la forma del patrimonio construido. Lo anterior en dos direcciones de cambio: la primera de habitacional a comercial y la segunda de comercios y servicios de proximidad y tradicionales a unos de prestigio con vocación turística e internacional. Una gentrificación que se concretiza

10 Carrión, 2007; Vergara, 2013, Casellas, 2012. 
en el uso preferencial de turistas de alto poder adquisitivo de los elementos patrimoniales más importantes de una ciudad. Una gentrificación que se da tanto en los espacios privados como en los espacios públicos por la tendencia de los primeros a asegurarse, protegerse y expandir sus actividades de consumo al exterior. Esa gentrificación define la transformación de la estructura social de varios puntos de los sectores centrales patrimoniales. En ellos se presenta una sustitución de usuarios y la introducción de una cuota de habitantes de clases medias y medias altas, que sustituyen a las clases populares. Lo anterior acentúa las diferencias sociales en una escala territorial. Esa adaptación es conducida por las prácticas turísticas y de consumo cultural del que son objeto los edificios y espacios urbanos más relevantes del patrimonio arquitectónico de una ciudad.

\section{EL TURISMO Y LA TRANSFORMACIÓN DE TIPOLOGÍAS ARQUITECTÓNICAS: GENTRIFICANDO EL PATRIMONIO CONSTRUIDO}

La gentrificación que comienza a caracterizar algunos polígonos de los centros históricos protegidos en Latinoamérica y en México, es conducida por el consumo turístico de clases medias y altas tanto nacionales como extranjeras. Ahora bien ese consumo turístico tiene un fuerte componente cultural, histórico y espacial, es decir se centra en el patrimonio edificado. El sociólogo británico John Urry $^{11}$ nos explica que existe una nostalgia por el pasado que caracteriza uno de los valores de la sociedad contemporánea (consumista y postmoderna). Dicha nostalgia impulsa la comercialización de experiencias turísticas asociadas al patrimonio que nutren el capital cultural, el poder simbólico y el prestigio de las clases sociales medias y medias altas.

En ese tenor, el patrimonio construido se vuelve el componente central del creciente turismo masivo en las ciudades patrimoniales a nivel mundial, particularmente en Europa occidental y en Latinoamérica. Ahí el patrimonio arquitectónico es un componente detonador del prestigio turístico de un destino, al mismo tiempo que la materia prima que sustenta el consumo cultural de los visitantes. Detonador porque justifica parte de los atributos de un centro histórico para ser merecedor de títulos nacionales e internacionales que sirven de marca de explotación turístico-comercial por ejemplo el de "Patrimonio de la Humanidad" (UNESCO) o el de "Pueblo Mágico" (SECTUR México) ${ }^{12}$. Materia prima porque se vuelve objeto de admiración,

11 Urry, 1990, p. 87.

12 Secretaria de Turismo de México, institución federal encargada de planificar y promover la actividad turística de ese país. 
entonces de consumo, cuya explotación ahora se da con base en usos de atracción turística o infraestructura de servicios turísticos: museo, teatro, ópera, galería, boutique, tienda de suvenires, hotel, restaurante, estacionamiento, etc.

No estamos omitiendo una de las cualidades que han tenido las políticas de conservación y las declaratorias de títulos patrimoniales sobre lo construido: su conservación y su restauración. En ese sentido en buena parte de los casos de las ciudades patrimonializadas, las mexicanas por ejemplo, se ha propiciado la reinversión inmobiliaria en zonas protegidas que cuentan siempre con alto potencial de comercialización turística ${ }^{13}$. Lo que planteamos aquí es que la conservación patrimonial no necesariamente implica una restitución o reapropiación para el conjunto de la sociedad que históricamente ha producido y mantenido esos soportes espaciales. Apropiación e interpretación que dan todo su sentido al valor patrimonial es decir su autenticidad $^{14}$. La denuncia va a esa parte de la patrimonialización en la que surge como una forma de exclusión social basada en la capacidad de consumo, una gentrificación apoyada en la implantación de nuevos usos y tipologías arquitectónicas, ad hoc a los intereses de las clases superiores sean habitantes o visitantes.

\footnotetext{
13 Delgadillo, 2009 y 2011.

14 Choay, 2006, p. 262.
}

\section{Metodología}

El trabajo aquí presentado explora aquellas intervenciones de conservación y restauración que tienen un efecto cuestionable sobre el valor cultural del patrimonio construido. Es decir proyectos con vocación turística y/o cultural, cuyas adaptaciones y modificaciones a la tipología arquitectónica tradicional implican una transformación radical de su valor patrimonial ${ }^{15}{ }^{16}$. El riesgo es amplio y bastante más frecuente de lo que parece. En la transición a la realidad de las políticas de planeación y administración urbana de sectores turistificados, se da un proteccionismo de fachadas que disimulan estructuras internas funcionales, formales, constructivas y de instalaciones, cuya finalidad es la rentabilidad y cuyo valor cultural es escaso o bien nulo.

Igualmente, este estudio atiende a una de las expresiones más acabadas de la gentrificación como efecto de exclusión social y espacial, la del turismo sobre el patrimonio. Es decir la reutilización de edificios protegidos para uso hotelero. Y siendo más específicos, el reúso en la categoría de mayor lujo, la de los hoteles boutique o las de 4 y 5 estrellas. En esa categoría se acentúa la desigualdad del disfrute patrimonial no solo entre grupos sociales

\footnotetext{
15 Navarrete, 2015, p. 133.

16 Emre, 2003, p. 181.
} 
sino entre locales y visitantes, siendo estos los más favorecidos por su mayor poder adquisitivo.

Se realizó una investigación de tipo mixto sobre las transformaciones urbano-arquitectónicas asociadas a la hotelería de alta gama en el centro histórico de la ciudad de Guanajuato. Se desarrolló una investigación cuantitativa y cualitativa cuyo principal instrumento fue una matriz de observación para los edificios patrimoniales. Igualmente el estudio se logró por medio de un trabajo documental y consulta de estadísticas de diversas instancias locales y estatales, asociadas al turismo y a la conservación patrimonial.

Para determinar la muestra se consultaron tres bases de datos disponibles en el año 2015, la del Directorio Nacional de Unidades Económicas (DNUE) del Instituto Nacional de Estadística, Geografía e Informática (INEGI), el de la Asociación Mexicana de Hoteles Delegación Guanajuato, y la de la Secretaría de Finanzas del Estado de Guanajuato sobre los establecimientos hoteleros de categoría alta. Además se realizó un recorrido en el perímetro del centro histórico para detectar nuevos establecimientos que por una apertura reciente no hubiesen sido considerados en los registros oficiales o bien otros que hayan desaparecido. Se identificaron así 15 unidades de análisis de la hotelería de lujo en el centro histórico de la ciudad de Guanajuato.

Por otro lado se consultaron las bases del catálogo de monumentos históricos del Instituto Nacional de Antropología e Historia (INAH) para determinar los hoteles de alta categoría que coincidían con edificios protegidos. Igualmente el perímetro de análisis fue el límite del Centro Histórico de la Ciudad de Guanajuato establecida por el propio organismo. Cabe mencionar que existen en la ciudad varios establecimientos hoteleros de lujo pero que se encuentran fuera del centro histórico, sobre todo en antiguos cascos de haciendas ${ }^{17} \mathrm{o}$ bien en edificios no protegidos.

Se realizó la consulta de la ficha más antigua del catálogo de monumentos históricos del INAH que correspondía a cada edificio patrimonial retenido, la mayoría de ellas con fecha de elaboración de entre 1988-1991 (13 casos) y de 1994 (2 casos). Luego se efectuaron visitas de campo a cada una de las unidades de análisis para cotejar con

17 El término "hacienda" en México designa fincas de gran tamaño con fines de explotación agrícola o minera. A estas últimas se les conoce como haciendas de beneficio por el tratamiento de la plata que en ellas se daba y son del tipo que encontramos en los edificios patrimoniales de la ciudad de Guanajuato. Esa figura de explotación latifundista estuvo vigente desde la época virreinal hasta al menos el inicio de la Revolución Mexicana de 1910. 
la información de las fichas e identificar por medio de las matrices las principales transformaciones arquitectónicas de los edificios y de su uso de suelo. Se realizaron, los respectivos levantamientos fotográficos y topográficos y el análisis de la tipología arquitectónica de cada uno. En caso de acceso restringido al edificio se recurrió al sitio de Internet del hotel donde se encontraron imágenes en la galería de fotos del establecimiento.

Paralelamente se consultaron los expedientes para permiso de construcción de los proyectos arquitectónicos de los edificios para uso hotelero, turístico y/o comercial presentados ante el INAH para su reconversión. En ellos se detectaron las principales modificaciones propuestas dentro de los términos de conservación de ese Instituto y que en su momento fueron aprobados.

Se produjo una cartografía temática del centro de la ciudad con los hoteles y los edificios patrimoniales en coincidencia para analizar su patrón de distribución. En términos urbanos y específicamente de exclusión socio-espacial, la cartografía permitió detectar los perímetros donde se concentran los hoteles de lujo. Ello da cuenta también de los radios en los cuales el uso habitacional ha disminuido con lógicas de desplazamiento de población. Igualmente da cuenta de los perímetros urbanos en los que por uso y consumo del espacio, tanto público como privado, los usuarios de clases menos acomodadas pueden ser también desplazados.

Finalmente, para determinar la magnitud de la transformación urbana y de la dinámica excluyente del turismo elitista y en general del turismo, se consultaron las bases municipales de catastro en las que se establece por cada predio, las superficies en metros cuadrados para uso hotelero, turístico y/o comercial. En cuanto al área del espacio público (banquetas, portales, plazas y jardines) con fines de consumo, se consultaron las bases de datos de la dirección de fiscalización del municipio de Guanajuato sobre la cantidad de metros cuadrados rentados a particulares para servicios turísticos (restaurantes y comercio). 


\section{TABLA 1: INSTRUMENTO DE ANÁLISIS DE LOS EDIFICIOS PATRIMONIALES DE HOTELERÍA DE LUJO}

\begin{tabular}{|c|c|c|}
\hline \multicolumn{3}{|c|}{ Contenido de la matriz de observación } \\
\hline Características & Indicadores & Evaluación \\
\hline Aspectos estructurales: & $\begin{array}{l}\text { Fachada, muros, espesor de muros, entrepi- } \\
\text { sos, forma de entrepisos, cubiertas, forma de } \\
\text { cubiertas. }\end{array}$ & $\begin{array}{l}\text { Estado de conservación. } \\
\text { Material de construcción. } \\
\text { Modificaciones a la tipología original. }\end{array}$ \\
\hline Aspectos expresivos: & $\begin{array}{l}\text { Color de fachada, colores interiores, materiales } \\
\text { de recubrimiento, ornamentación, estructuras } \\
\text { adheridas (anuncios o lonas). }\end{array}$ & $\begin{array}{l}\text { Estado de conservación. } \\
\text { Material de construcción. } \\
\text { Modificaciones a la tipología original. }\end{array}$ \\
\hline Aspectos funcionales: & $\begin{array}{l}\text { Extensiones, remodelaciones e instalaciones } \\
\text { especiales. }\end{array}$ & $\begin{array}{l}\text { Modificaciones a la tipología original. } \\
\text { Adaptaciones estructurales. }\end{array}$ \\
\hline Uso de suelo: & $\begin{array}{l}\text { Habitacional, Comercial, Equipamiento y/o } \\
\text { Mixto. }\end{array}$ & $\begin{array}{l}\text { Modificación al uso original. } \\
\text { Expansión al espacio público. }\end{array}$ \\
\hline
\end{tabular}

Fuente: Elaboración del autor.

\section{Resultados}

\section{TRANSFORMACIONES AROUITECTÓNICAS, EL PATRIMONIO AL SERVICIO DE LA GENTRIFICACIÓN}

Con base en la observación de campo y contrastando sus resultados con la información de los registros del Catálogo de Monumentos Históricos de la ciudad de Guanajuato proporcionados por el INAH, se han identificado las principales alteraciones en los inmuebles de alojamiento de lujo. Cabe recordar que la tipología arquitectónica protegida de la vivienda tradicional de Guanajuato está representada por construcciones del siglo XIX, edificios de dos niveles en crujías con zaguán, escaleras, patio central descubierto y habitaciones dispuestas a su alrededor. En la parte inferior se 
encuentran las habitaciones de sala, comedor, despacho, cocina y en algunos casos recámaras. En la parte superior esencialmente recámaras y habitaciones familiares. De los 15 casos analizados, 12 tenían uso original de habitación 1 de hotel y 2 de hacienda de beneficio. Para finales de la década de los ochentas del siglo pasado, 8 de ellos poseían un uso habitacional, 2 eran hoteles desde inicios del siglo XX y 5 tenían uso mixto (habitacionalcomercial o habitacional-oficina). Cabe mencionar que dos de estos inmuebles H5 y H14 se encontraban en ruinas en 1988 según el catalogo del INAH, un tercero $\mathrm{H} 3$ se encontraba parcialmente en ruinas, pero habitable. En esos edificios la adaptación a hoteles de lujo fue una reconstrucción que respetó únicamente la tipología de la fachada original que en todos los casos seguía en pie.

En orden de grado de afectación y frecuencia de la misma, tenemos que las principales modificaciones del patrimonio construido con uso de hotelería de lujo son:

- Las adecuaciones requeridas para instalaciones de lujo y de alto nivel de confort. Se identificaron tres elementos con el mayor grado de afectación a la conservación de la tipología original: el ascensor, la piscina y el spa. La frecuencia de este tipo de alteraciones es de un tercio de los casos analizados, pero se ve sobre representada en las creaciones hoteleras más recientes, las registradas después de 2010 (cuatro unidades), en ese universo tres presentan esas intervenciones (H2, H5, H13 y H15). Su nivel de afectación se considera el más elevado debido a que se presentan en varias de las edificaciones más antiguas de la ciudad. Es decir, afecta a los elementos más destacados del patrimonio, edificios originarios del siglo XVIII y XIX, que además son las construcciones más cercanas al centro geográfico de la ciudad.

- Las adecuaciones requeridas para instalaciones eléctricas, hidráulicas, sanitarias, de gas y de aire acondicionado. Por los requerimientos de comodidad del nicho de mercado turístico de alto standing, este tipo de instalaciones son de suma importancia para su funcionamiento. Ello implica importantes modificaciones a la estructura original del edificio conducidas principalmente por nuevos ductos así como por locales especiales con subestaciones eléctricas, calderas, sistemas hidroneumáticos y otras máquinas. Cuando no se altera la estructura por demolición, las redes de infraestructuras agregadas, tuberías y cables quedan ocultos con paneles falsos, lo que modifica la tipología de muros. Otra alteración se observa en el aspecto de la fachada a la cual se adhieren de forma expuesta las tuberías, registros y cables para suministro eléctrico y de gas. Con ese tipo de alteraciones tenemos las unidades: $\mathrm{H} 1, \mathrm{H} 2$, H3, H4, H5, H6, H10, H11, H12 y H13. 
- Las modificaciones a las estructuras por las nuevas cargas que necesitan un reforzamiento adosando de estructuras de concreto armado, columnas, trabes y losas. Ellas implican la perforación o reemplazo de cubiertas y/o pisos originales. Las unidades donde se presentaron este tipo de inserciones son: $\mathrm{H} 2, \mathrm{H} 3, \mathrm{H} 5, \mathrm{H} 10$, H13, H14 y H15.

- Las modificaciones por fusión y agrandamiento de ambientes según nuevas necesidades de espacios lujosos. Ello implica la demolición total o parcial de muros que permiten la unión de varias crujías ya sea para agrandar espacios, para hacer conexiones entre ellos o para adherir ampliaciones nuevas. Las intervenciones más graves a la estructura constructiva la representan los muros, los entrepisos y las cubiertas agregados o sustituidos con materiales distintos a los originales. Ellos están constituidos principalmente por tabique (rojorecocido o prefabricado) y por concreto armado. Otra estrategia de intervención sobre la estructura es la de muros divisorios, plafones y paneles falsos prefabricados de yeso, madera o vidrio. Estas adaptaciones estrictamente no son una amenaza directa al edificio puesto que su instalación y retiro implica ligeras intervenciones. Sus principales consecuencias se dan en el aspecto formal y expresivo de las edificaciones que puede cambiar radicalmente. Las 15 unidades de análisis presentaron este tipo de modificaciones.

- La utilización de estructuras agregadas para facilitar que algunos espacios sean circulables y/o habitables. Es el caso de escaleras, mezzanines, balcones, pasillos, cubiertas y azoteas convertidas en terrazas. Los materiales más utilizados son estructuras metálicas, de madera y/o de vidrio adosadas a la construcción original. Con este tipo de alteraciones encontramos a las unidades H13, H1, H8, H12, H5, H2 y $\mathrm{H} 9$.

- El incremento de uno o varios niveles a los inmuebles sin que se aprecien desde la fachada principal. Para lograrlo, lo más común es el elevamiento de pretiles y el repliegue al interior del predio de los pisos adheridos con respecto al paramento principal de la fachada catalogada. Una tercera parte de los inmuebles presentan adhesiones de al menos un nivel con respectivas modificaciones a aspectos formales (altura y ornamentación) que disimulan las ampliaciones verticales: $\mathrm{H} 2$, $\mathrm{H} 5$, H8, $\mathrm{H} 10$ y $\mathrm{H} 13$.

- Alteraciones en las proporciones de los vanos de las fachadas originales. Esta es una de las prácticas más comunes de alteración tipológica de los edificios habitacionales convertidos en hoteles de lujo. La fachada en la parte inferior, excepto el zaguán, alberga negocios con giros 
asociados al turismo, boutiques, cafés y restaurantes de marcas transnacionales que con frecuencia funcionan de forma independiente del hotel. Para permitir esas combinaciones de usos se recurre al tapiado de vanos hacia el interior de los patios, a la apertura de muros entre habitaciones para acrecentar la superficie de comercio y a la transformación de vanos de ventanas en vanos de puertas con acceso directo a nivel de calle. De esa forma se generan locales de unidades económicas diferentes, pero complementarias de los servicios turísticos de lujo. Así tenemos las unidades H1, H2, H3, H4, H5, H6, H7 y H9.

- Por último tenemos las alteraciones de tipo expresivo. En primer lugar se presenta una sustitución de aplanados de cal hidra en fachada por los base de mortero de cemento. En segundo lugar tenemos el cambio de color en fachadas con colores no tradicionales (tonos fríos y tonos pastel), ni contemplados en la paleta de colores del INAH (cálidos y tierra). En tercer lugar tenemos la adición de elementos decorativos y comerciales en fachada, como toldos, lonas y letreros; estos insertan a las fachadas nuevos tipos de materiales como luz neón, aluminio y acrílico. En cuarto lugar se presenta la sustitución de acabados en interiores para pisos y muros, discordantes de los originales. Se trata de azulejos y mosaicos tradicionales, de barro, cerámica y cemento que son sustituidos por vitro-piso industrial, alfombras, yeso, tapices, pastas, entre otros. Estas aplicaciones se ven acompañadas de la instalación de plafones, molduras y muros falsos que recrean elementos decorativos "tradicionales" con materiales modernos. La carpintería y la herrería tradicionales son otros elementos que se pierden. Los nuevos hoteles recurren a cancelería de aluminio, en consecuencia las puertas y ventanas exteriores tradicionalmente de madera son sustituidas por otras metálicas. Por último, el mobiliario semifijo es otro elemento que interviene en el nuevo aspecto de las fachadas de los edificios patrimoniales. Desde balcones, terrazas y patios, esos objetos toman relevancia por su tamaño y número: sombrillas, calefactores exteriores, luminarias, sillas y mesas visibles al exterior y en la fachada de los edificios. Las 15 unidades de análisis presentaron al menos una de estas alteraciones de tipo expresivo.

En síntesis, la tipología resultante en los edificios patrimoniales de uso habitacional convertidos a hospedaje de lujo es más o menos la siguiente: acceso a hotel por zaguán, el patio central se ha cubierto y convertido en lobby o en restaurante de comida internacional. Subdivisión del edificio para comercios en planta baja con fachada exterior. Fachada conservada, pero con vanos de ventanas transformados en vanos de puerta. Interior 
con importantes modificaciones tipológicas y estructurales. Las azoteas se convierten en terrazas para bares o restaurantes y en algunos casos para spa con jacuzzis y piscinas. Observamos entonces que las alteraciones en estos inmuebles tienen el fin de adaptarlos a su nuevo uso, sin embargo no en todos los casos se protege la integridad y autenticidad de las edificaciones. Se tiene como prioridad el máximo aprovechamiento comercial de las áreas pese a sus restricciones de conservación y a costa del propio valor del patrimonio construido.

\section{TRANSFORMACIONES URBANAS, TURISMO UNA MODALIDAD DE LA GENTRIFICACIÓN}

Una de las principales transformaciones urbanas que han conducido a la elitización de una parte importante del patrimonio histórico construido en el centro de Guanajuato ha sido la modificación del uso de suelo, otrora habitacional, al uso de servicios, de comercio y de hospedaje de lujo. Actualmente la totalidad de los inmuebles patrimoniales de la hotelería de lujo tienen uso mixtocomercial y el residencial se ha extinguido. Ello no solo en el inmueble en cuestión sino en los del contexto inmediato. Lo anterior por la dinámica de aglomeración económica de servicios que se genera en torno a un establecimiento de esta naturaleza. Aquí cabe señalar una sinergia que implica la instalación de otros hoteles de lujo, hoteles de menor categoría, restaurantes, cafeterías, boutiques, entre otros comercios y servicios que provocan que sus alrededores se gentrifiquen también. Se ha observado en nuestro caso de estudio que luego de la instalación de un hotel de lujo en un inmueble patrimonial, se sustituyen en los inmuebles aledaños los comercios tradicionales por otros de consumo turístico y de alta gama. Igualmente en las calles y plazas aledañas se presenta una mutación comercial. Así por ejemplo en la Plaza de la Paz, en la Calle de Allende y en la Calle Cantarranas, lugares de reciente creación de hoteles de lujo (H5, H7 y H8), se observa una sustitución importante de comercio tradicional y de proximidad, específicamente se tiene documentada la desaparición de tiendas de abarrotes, carnicerías, ferreterías, papelerías, librerías y zapaterías. En su lugar han aparecido cadenas internacionales de comida (Subway, 100 montaditos, pizzerías y bistrós), tiendas de conveniencia (Oxxo's), bares, boutiques de lujo y tiendas de suvenires. 
FIGURA 1: TIPOLOGÍA TRADICIONAL Y MODIFICACIONES RESULTANTES. EJEMPLO DE LA UNIDAD H5
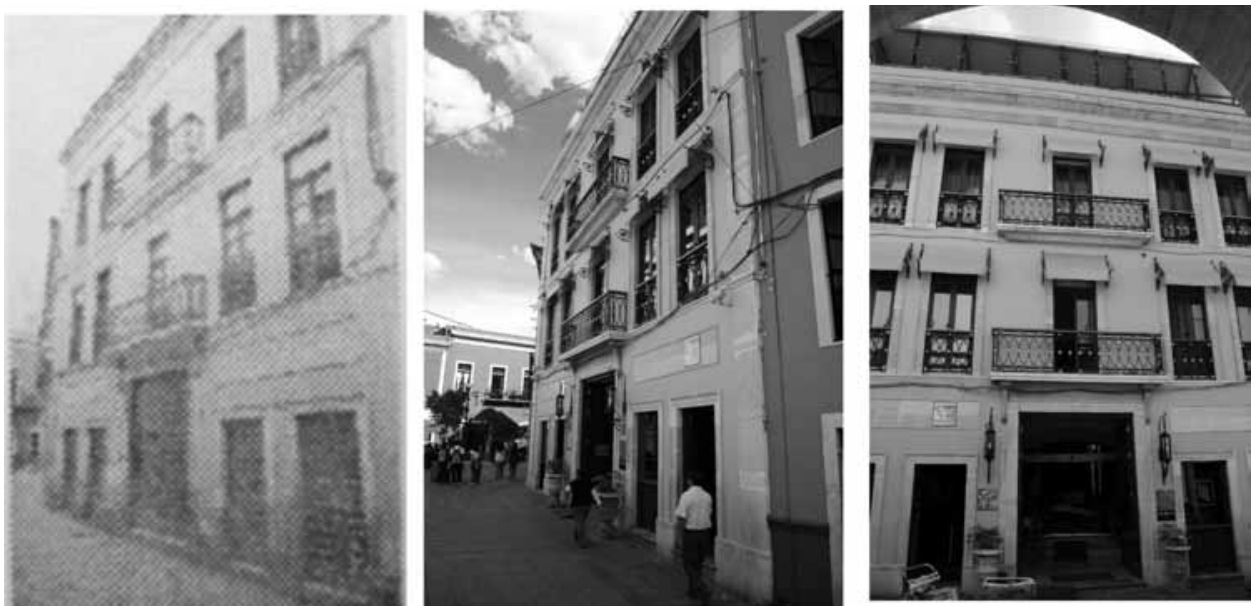

Fuente: Fotos Autor 2015

\section{FIGURA 2: TIPOLOGÍA TRADICIONAL Y MODIFICACIONES RESULTANTES. EJEMPLO DE LA UNIDAD H11}
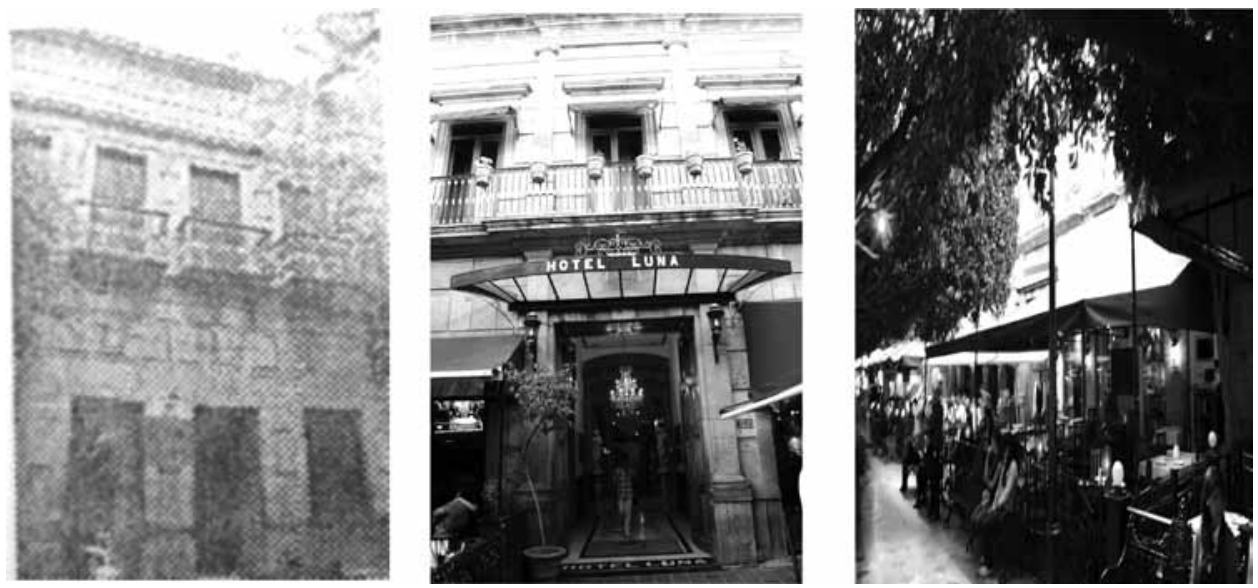

Fuente: Fotos Autor 2015 
MAPA 1. DISTRIBUCIÓN DE PLAZAS Y DE INMUEBLES CATALOGADOS CON USO DE HOTELERÍA DE LUJO EN EL CENTRO DE GUANAJUATO

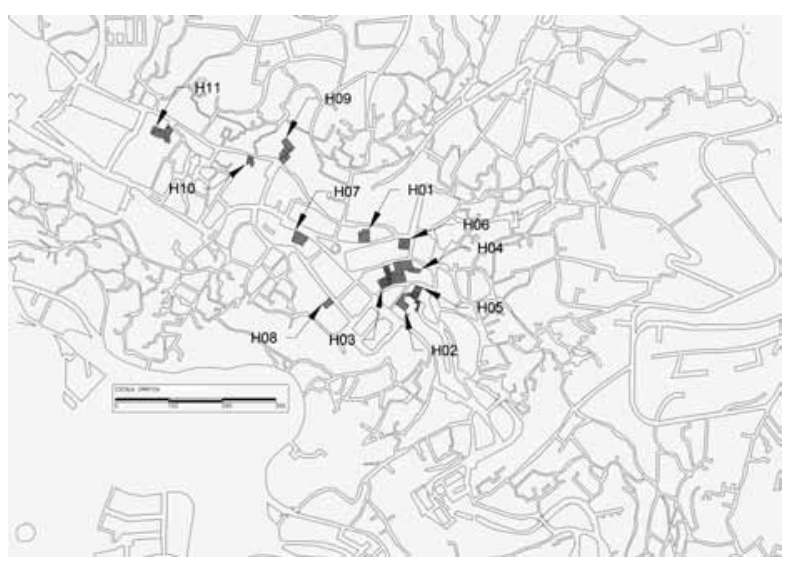

Fuente: Elaboración del autor.

\section{MAPA 3. DISTRIBUCIÓN DE INMUEBLES}

CATALOGADOS CON USO DE HOTELERÍA DE LUJO EN EL BARRIO DE SAN JAVIER EN GUANAJUATO

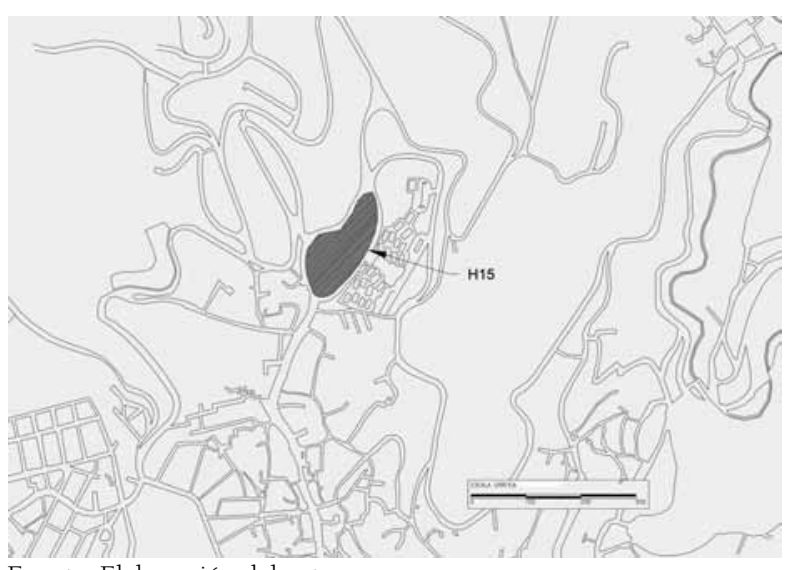

Fuente: Elaboración del autor.
MAPA 2. DISTRIBUCIÓN DE INMUEBLES

CATALOGADOS CON USO DE HOTELERÍA DE LUJO EN EL BARRIO DE LA PRESA EN GUANAJUATO

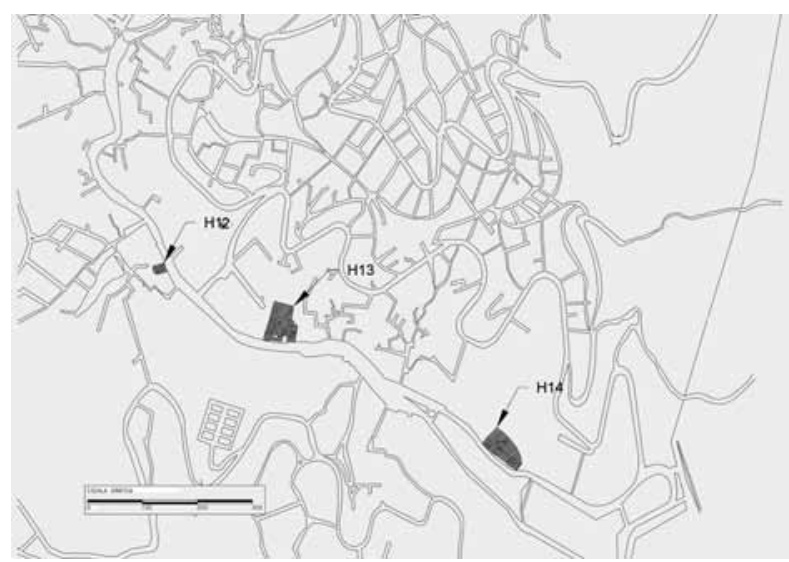

Fuente: Elaboración del autor.

FIGURA 3. OCUPACIÓN DEL ESPACIO PÚBLICO EN PLAZA Y CALLES ADYACENTES A LOS EDIFICIOS PATRIMONIALES MÁS DESTACADOS DE LA CIUDAD

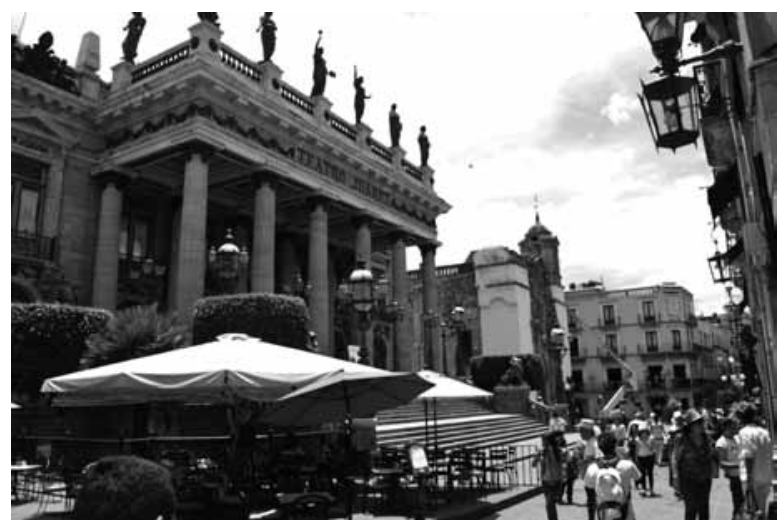

Fuente: foto autor 2015 
Los nuevos usos de los inmuebles patrimoniales conducen también una privatización del espacio urbano. Aquí los actores políticos son determinantes pues manifiestan un favoritismo empresarial. Así los efectos de la gentrificación no terminan en el límite del inmueble que se ha reconvertido en hotel o restaurante de lujo, sino que delimita, usa, asegura y controla el espacio público contiguo a su fachada. En el caso de Guanajuato el poder municipal se vuelve clave en este fenómeno, pues a pesar de la postura y recomendaciones del nivel federal (Instituto Nacional de Antropología e Historia), el poder local permite el usufructo de banquetas y explanadas a restaurantes, hoteles y boutiques a razón de obtener 342 pesos mensuales (unos 23 dólares americanos en 2015) por metro cuadrado. Hacia el año 2014 se tenían registrados según el servicio local de fiscalización municipal, $1.252 \mathrm{~m}^{2}$ de uso comercial de espacio "público" rentado a hoteles y restaurantes hacia los frentes de los inmuebles, en plazas y calles adyacentes. La mayoría de esas superficies se encuentran en plazas como la de San Fernando, la de la Paz y el Jardín Reforma.

Finalmente, los actores públicos y los empresariales conducen una gentrificación real y simbólica, no solo por los usos excluyentes en términos de consumo, sino también por medio del control y la seguridad pública de los perímetros turísticos en los que se instala la hotelería de lujo. Las entradas a los establecimientos hoteleros están resguardadas por policías privados y las calles por policías "turísticos". Su misión oficial es regular la seguridad, pero en la práctica se han vuelto factor de presión sobre usuarios poco convenientes para la buena imagen turística de la ciudad. Específicamente se encargan de regular la presencia de indigentes, de comerciantes ambulantes y transeúntes de clases sociales humildes. Dichos grupos en los que recae una exclusión simbólica son representados por mujeres, niños, jóvenes y adultos mayores de origen indígena, migrantes de regiones más pobres del estado o bien habitantes de zonas marginales de la misma ciudad de Guanajuato.

\section{Discusión}

\section{RELACIÓN TURISMO ELITISTA-PATRIMONIO}

Los resultados sobre las transformaciones arquitectónicas del patrimonio construido para fines de consumo de la más alta categoría turística, muestran una serie de relaciones que actualmente dirigen la transformación socio-espacial de un buen número de ciudades históricas en el mundo. En ellas el patrimonio juega un rol ambivalente ante la gentrificación turística, él es a la vez el recurso potencial de explotación cultural y de ocio, que justifica las inversiones hoteleras; y a la vez él se convierte en el objeto principal de las adaptaciones tipológicas de la arquitectura según los nuevos 
modos de uso y de consumo la ciudad turistificada. El caso aquí estudiado permite identificar la relación entre el incremento de establecimientos hoteleros de alta gama, es decir una elitización del turismo como forma de gentrificar la ciudad; y la transformación/pérdida del patrimonio arquitectónico, específicamente por una adaptación tipológica de tipo fachadista. Aquí podemos hablar de intervenciones ambiguas de conservación que si bien en la teoría no son una destrucción o reemplazo de los inmuebles protegidos; en la realidad si son importantes adaptaciones que trastocan tanto aspectos estructurales como aspectos expresivos. Estamos hablando de fachadas conservadas a la vez que modernizadas, pero que esconden transformaciones mayores de los inmuebles que amenazan el valor patrimonial de los mismos.

Se ha identificado una tendencia a la expansión espacial de este tipo de hoteles así como a la proliferación de nuevas implantaciones en edificios patrimoniales restaurados. Aunque se reconoce que el mercado de turistas de lujo es pequeño comparado con el turismo masivo más popular, lo cierto es que él es de alta rentabilidad y justifica seguir invirtiendo en ese nicho antes de que se sature esa oferta de hospedaje. Podemos ejemplificar esta tendencia con el caso del establecimiento H-13 ubicado en el barrio de la Presa (Mapa 2), que ha adquirido en 2013 dos inmuebles contiguos de casas habitación, catalogadas y protegidas por el INAH para incrementar su capacidad de habitaciones y servicios.
En este caso estamos hablando de una sola empresa hotelera que ha fusionado 3 inmuebles patrimoniales en los cuales ha intervenido siguiendo los principios descritos en la sección de resultados sobre la adaptación tipológica de la arquitectura.

De lo planteado anteriormente se deriva que la reutilización del patrimonio construido aparece como uno de los soportes donde la gentrificación toma una dimensión real y tangible de exclusión social, económica, cultural y espacial. Así podemos establecer una relación entre la gentrificación por el turismo y la mutación arquitectónica y urbana del patrimonio de una ciudad.

\section{RELACIÓN DE ACTORES: GOBIERNO-EMPRESA- SOCIEDAD}

Desde la declaratoria de la ciudad de Guanajuato como Patrimonio de la Humanidad por parte de la UNESCO en 1988, la presión por la explotación turística ha ido en aumento. En ella diferentes niveles de gobierno, tanto municipal como federal, han participado para que en varios casos, la turistificación de la ciudad se de en detrimento del patrimonio, a favor de grupos sociales privilegiados y de sus círculos empresariales aliados. En varios proyectos se pueden rastrear conflictos de interés en los que los compadrazgos locales se anteponen al estricto cumplimiento de las normas de protección patrimonial. Recientemente podemos citar tres casos en los que el principio de protección 
patrimonial es en realidad una negligencia disfrazada de cumplimiento de facultades de las instituciones implicadas. Ha sido el caso de la privatización del espacio público al frente del Teatro Juárez y la utilización de mobiliario urbano inadecuado que demerita la imagen urbana de la ciudad ${ }^{18}$, interfiriendo con la visual de uno de los edificios monumentales más importantes de la ciudad como lo muestra la figura 3. Igualmente ha sido el caso ya comentado del hotel boutique $\mathrm{H}-13$ en el barrio de la Presa que durante su ampliación ha incumplido con varias normas urbanas y patrimoniales afectado estructuras de inmuebles vecinos igualmente catalogados $^{19}$. En ambos casos el presidente municipal en turno tiene vínculos familiares o profesionales con los inversionistas hoteleros. Por último, en el hotel boutique $\mathrm{H}-15$ se ha documentado la destrucción de un muro original de la hacienda de beneficio minero del siglo XVII sobre el que se realiza una ampliación de habitaciones.

El funcionamiento de las arbitrariedades es más o menos este: el nivel federal, por medio del INAH emite recomendaciones a las instancias municipales, ellas las reciben, pero no las acatan o no les dan curso. Así la primera institución se deslinda de responsabilidad y la segunda incumple. Por parte de los empresarios se observa que prefieren pagar sanciones o en todo caso no respetar los

\footnotetext{
18 Ochoa, 2014.

19 Espinosa, 2014
}

sellos de clausura de la obra de renovación, antes que detener sus intervenciones sobre los inmuebles catalogados.

\section{CONSIDERACIONES TEÓRICAS DEL CASO DE GUANAJUATO PARA ENTENDER LA GENTRIFICACIÓN EN LATINOAMÉRICA}

A diferencia de las modalidades de gentrificación documentadas en las ciudades de los países del norte, en México y en particular en nuestro caso de estudio, las prácticas socio-espaciales excluyentes son conducidas por el financiamiento del Estado en un primer momento. El Capital actúa en un segundo turno para beneficiarse de las inversiones del erario, y eso atañe directamente a las políticas de preservación patrimonial de una ciudad. En Europa y en Estados Unidos de Norteamérica, la transformación del patrimonio y la sustitución de clases se ha dado principalmente por dinámicas sociales y económicas, impulsadas por el mercado y que varios trabajos definen con el concepto del diferencial de renta o el Rent Gap. En contraste en los centros patrimoniales de las ciudades mexicanas y varias latinoamericanas, el Estado y las instituciones internacionales han sido los inductores de dinámicas urbanas de revitalización, financiando con fuertes sumas de dinero para proyectos de 
restauración, protección y "rescate" de patrimonio, tanto a escala de un monumento, edificio público y espacios urbanos. En el caso aquí estudiado, las instituciones nacionales (Secretaría de Turismo, Instituto Nacional de Antropología e Historia, Direcciones Estatales y Municipales de Planeación Turística y Urbana), e internacionales (UNESCO, Organización Mundial de Turismo y Banco Interamericano de Desarrollo), han inducido la comercialización de ciudades y sus espacios patrimoniales. Ellas promueven las dinámicas mercantilistas de las cuales son sobre todo las élites económicas locales e internacionales, asociadas a la explotación turística las que más se benefician.

En Guanajuato primero fueron una serie de circunstancias endógenas las que permitieron que se produjera, luego se conservara un patrimonio edificado significativo, para que posteriormente fuerzas exógenas lo hicieran explotable en términos turísticos. Lo que aquí pasó fue que en general la ciudad de Guanajuato vio mermado su crecimiento gran parte del siglo XX. La principal razón fue el decaimiento de la actividad minera, ello implicó poco dinamismo económico y demográfico que jugó en favor de la preservación de un centro histórico heredado del apogeo de los siglos XVIII y XIX. Hacia las últimas décadas del siglo XX y particularmente con la declaratoria en 1988 de la UNESCO como Patrimonio de la Humanidad, el centro se volvió otra vez atractivo al Capital. Fueron esas declaratorias y las inversiones institucionales nacionales e internacionales de conservación las que rehicieron atractivo al centro patrimonial para la llegada de inversiones, esta vez con fines turísticos en edificios particulares de uso habitacional.

En síntesis, la experiencia de varias ciudades medias mexicanas como Guanajuato, muestra una modalidad de gentrificación, la del patrimonio urbano por medio del consumo turístico. Es decir un binomio gentrificación-turistificación que pone en cuestión la conservación del valor cultural de los edificios e impone dinámicas de exclusión sociales y territoriales.

\section{Conclusión}

Este estudio ha mostrado cómo en ciertos casos el turismo gentrifica varios de los edificios y de los sitios más notables del patrimonio urbano de una ciudad. Lo anterior haciéndolos productos de consumo para un mercado de visitantes de alto poder adquisitivo. En ese proceso las transformaciones espaciales pueden contrariar la conservación, la originalidad y el valor patrimonial de la arquitectura y del espacio urbano. Igualmente en ese proceso se puede contravenir a los valores identitarios y de apropiación de la sociedad local que sustenta el patrimonio construido y que paradójicamente motivan la visita de turistas. El caso de Guanajuato 
representa una tendencia que puede tomar diferentes matices según el grado de turistificación de un centro histórico. A su vez ese grado depende de las condiciones endógenas del tejido social y habitacional, de la conservación patrimonial, de la diversidad de usuarios y de la multifuncionalidad de usos que pueden representar un contrapeso a la gentrificación. Con ello aclaramos que no todas las ciudades patrimonializadas pierden de facto sus atributos culturales. Existen varias de ellas que contienen bien los procesos de exclusión a causa esencialmente de una menor presión turística (frecuentación y servicios). En ese sentido el caso de Guanajuato abre la posibilidad de realizar, en estudios posteriores un trabajo comparativo con ciudades patrimoniales similares, donde se identifiquen los factores potenciales comunes de la gentrificación y de la turistificación.

Uno de los objetivos de esta investigación fue explorar otros indicadores de la gentrificación, específicamente aquellos relacionados con la arquitectura patrimonial. Con lo anterior también se abre la discusión hacia cómo el turismo vehicula dinámicas de exclusión social y territorial en ciudades latinoamericanas patrimonializadas. El referente empírico aquí tratado, es decir la transformación del espacio protegido de una ciudad turística, puede ser considerado como un caso particular. Sin embargo, también puede servir de referente para el análisis de uno de los múltiples frentes de avance que tiene la gentrificación en México. Así, él abre la posibilidad de establecer y de explorar nuevas relaciones con los factores del turismo, que inciden en el surgimiento de la gentrificación, como pueden ser: el comportamiento del mercado de suelo, la erosión del tejido social en centros patrimoniales, la limitación del derecho a la ciudad histórica para los menos afortunados, la limitación de la participación ciudadana y la precarización de la ciudadanía en el uso y gestión del patrimonio. Aspectos que en nuestra condición de investigadores o productores del espacio urbano reclaman una urgente atención.

\section{Bibliografía}

ASCHER, François. Les nouveaux principes de l'urbanisme. Paris, Editions de l'Aube. 2001. 110 p. ISBN 2-87678-992-2.

BOLDRINI, Paula y MALIZIA, Matilde. Procesos de gentrificación y contragentrificación. Los mercados de abasto y del norte en el gran San Miguel de Tucumán (noroeste argentino). Revista INVI. 29(81): 157-191, agosto 2014. ISSN 0718-8358. DOI 10.4067/SO718-83582014000200005.

CARRIÓN, Fernando. El financiamiento de la centralidad urbana: el inicio de un debate necesario. En: CARRIÓN, Fernando. Financiamientos de los centros históricos de América Latina y el Caribe. Quito, FLACSO, Lincoln Institute of Land Policy. 2007. 413 p. ISBN 978-9778-67-127-6. 
CASELLAS, Antonia; DOT-JUTGLA, Estebe y PALLARES-BARBERA, Montserrat. Artists, cultural gentrification and public policy. Urbani Izziv Urban Challenge. 23(1): 104-114, diciembre 2012. ISSN 0353-6483.

CASGRAIN, Antoine y JANOSCHKA, Michael. Gentrificación y resistencia en las ciudades latinoamericanas. El ejemplo de Santiago de Chile. Andamios, Revista de Investigación Social. 10(22): 19-44, mayo 2013. ISSN 1870-0063.

CHOAY, Françoise. Pour une anthropologie de l'espace. Paris, Éditions du Seuil. 2006. 412 p. ISBN 978-2-02-082533-7.

DELGADILLO, Víctor. Patrimonio histórico y tugurios: Las políticas habitacionales y de recuperación de los centros históricos de Buenos Aires, Ciudad de México y Quito. México, Universidad Autónoma de la Ciudad de México. 2011. 670 p. ISBN 978-607-7798-44-6.

Patrimonio urbano y turismo cultural en la Ciudad de México: las chinanpas de Xochimilco y el centro histórico. Andamios, Revista de Investigación Social. 6(12): 69-94, diciembre 2009. ISSN 1870-0063.

DEWAILLY, Jean-Michel. Mise en tourisme et touristification. En: AMIROU, Rachid. Tourisme et souci de l'autre. París, L'Harmattan. 2005. p. 29-34. ISBN 978-274-758-8621.
EMRE, Gunce. Tourism and local attitudes in Girne, Northern Cyprus. Cities. 20(3): 181-195, junio 2003. ISSN 0264-2751.

ESPINOSA, Verónica. Denuncian afectaciones por ampliación de hotel en Guanajuato. [En línea]. Proceso 16 octubre 2014. [Fecha de consulta: 8 mayo 2015]. Disponible en: http://www.proceso.com. $\mathrm{mx} / \mathrm{p}=385026$.

FLORIDA, Richard. The rise of the creative class... And how it's transforming work, leisure, community and everyday life. New York, Basic Books. 2002. 404 p. ISBN 9780465024766.

GLASS, Ruth. Introduction: aspects of change. En: London: Aspects of change. London, MacGibbon \& Kee. 1964. Centre for Urban Studies report nro. 3.

HARVEY, David. La condición de la postmodernidad. Buenos Aires, Amorrortu. 1998. 401 p. ISBN 950-518-652-5.

MONGIN, Olivier. La condition urbaine, la ville à l'heure de la mondialisation. Paris, Editions du Seuil. 2005. 325 p. ISBN 2-02-081983-X.

MONNET, Jerome. Usos e imágenes del centro de la Ciudad de México. México D.F., Departamento del Distrito Federal/Centro de Estudios Mexicanos y Centroamericanos.1995. 372 p. ISBN 9789686029345

NAVARRETE, David y PINEDA, Alma. Tourisme religieux et transformations urbaines au Mexique. En: FABRY, Nathalie; PICON-LEFEBVRE, Virginie y PRADEL, Benjamin. Narrations touristiques et fabrique des territoires. Paris, L'oeil d'or. 2015. p. 117-134. ISBN 978-2913661-66-0. 
OCHOA, Alfonso. El municipio es quien decide sobre la sobrilla. [En línea]. El Correo. 29 octubre 2014. [Fecha de consulta: 30 mayo 2015]. Disponible en: http://periodicocorreo.com.mx/ el-municipio-es-quien-decide-sobre-sombrilla/.

PAOUOT, Thierry. Terre urbaine: cinq défis pour le devenir urbain de la planète. Paris, La Découverte. 2006. 221 p. ISBN 2-7071-4943-8.

\section{SABATINI, Francisco; SARELLA, María y VÁSQUEZ,} Héctor. Gentrificación sin expulsión, o la ciudad latinoamericana en una encrucijada histórica. Revista 180. (24): 18-25, 2009. ISSN 0718-669X.

SASSEN, Saskia. La ville globale: New York, Londres, Tokyo. Paris, Descartes et Compagnie. 1996. 530 p. ISBN 9782910301453.

URRY, John. The tourist gaze: leisure and travel in contemporary societies. London, Sage. 1990. 180 p. ISBN 0803981821.

VERGARA, Carlos. Gentrificación y renovación urbana. Abordajes conceptuales y expresiones en América Latina. Anales de Geografía. 33(2): 219-234, diciembre 2013. ISSN 0211-9803. 